\title{
Value -Based Maintenance Management Model for University Buildings in Malaysia-A Critical Review
}

\author{
Arazi Idrus, Mohd Faris Khamidi \& Olanrewaju Abdul Lateef, A \\ Department of Civil Engineering, Universiti Teknologi PETRONAS \\ Bandar Seri Iskandar 31750 Tronoh, Perak Darul Ridzuan \\ E-mail: olanrewaju20002000@yahoo.com
}

\begin{abstract}
The essence of building maintenance is to increase the service life of a building by delaying deterioration, decay and failure. Building maintenance must therefore be considered as a strategic process if the value of a building is to be sustained. Building maintenance management is a complex and multi-faceted thought process that involves planning, directing, controlling and organizing maintenance services for the sustenance of the value of a building. It entails making intricate decisions under complex algorithms, uncertainty and risks within organizational resources. The purpose of this paper is to propose an alternative maintenance management model for university buildings in Malaysia. The proposed model reflects current thinking on building maintenance management. A number of studies have investigated the maintenance management of university buildings in Malaysia; however, all the studies have observed maintenance management procedures that are corrective and condition based. Nonetheless, this is contributing to the spate of maintenance backlogs and the lack of value delivery to the stakeholders. Although the research specifically focused on university buildings, many public and private sector organizations face similar maintenance management problems. Therefore this research has broader applications. The outcome of this research is to come up with a prototype maintenance management model that can facilitate university institutions to carry out buildings maintenance management services that meet the expectations and perceptions of the stakeholders.
\end{abstract}

Keywords: Maintenance management, University buildings, Malaysia, Value, Users

\section{Introduction}

This paper is part of an ongoing research project on building maintenance management. The overall aim of the research of which this paper forms part of is to develop a building maintenance management that is based on the concept of value. A building requires maintenance to ensure its optimal performance over its life cycle. The value of a building from the user's perspective can be viewed as the measure of how efficiently and effectively a building meets the users' needs with the available resources. However, there is no conclusive literature on how well university buildings are maintained in Malaysia. However, it is contended that university buildings like other public buildings in Malaysia are not well maintained. This is based on the premises that across the whole spectrum, similar or the same maintenance management systems are applied to public buildings in Malaysia even though previous studies have found that the maintenance management systems for the university buildings are not cost-effective. In part, a salient point in this research is to incorporate value criteria and concepts within the process of maintenance management of university buildings. The premise is very much that the focus of maintenance should be driven by the building users. The focus of most public organizations on building maintenance has been usually corrective or preventive and is mainly based on the condition of the buildings as revealed through inspection. According to this, the condition of the building is revealed through a condition survey without recourse to the stakeholders' perceptions and expectations. However, the only reason for providing buildings is to enable them to be used by their occupants. It is not the condition of the building that really matters but the functions which the building is performing. It is therefore, the needs of the buildings users that should dictate the maintenance management processes in terms of policy, purposes and objectives. As a result, it is pertinent for those reasons to consider maintenance management as a value added initiative that seeks to be addressing user needs. Such a consideration is entirely consistent with the principle and philosophy of value management. Value is the relationship between functional performance and the resource used to provide the function (Figure 1). Value is used in this research to define the user's / owner-occupiers satisfactions with the quality of the maintenance service provided and the resource used. Value based maintenance management puts the user's value system at the centre of initiating maintenance service. A university cannot fail to meet the requirements of its clients (users). In fact, these days' universities usually promote the design and performance of their buildings to woo students. The paper is structured as 
follow; it commences in section 1"theoretical framework" with the background on the maintenance management procedures. In the last section, "Synopsis and Further Research" the conclusion of the paper are provided and continue to provide information on the fundamental weaknesses in the maintenance management procedures which are noted to be factors leading to building maintenance backlog and poor service delivery.

\section{Theoretical Framework}

Buildings are designed to address some technical problems as identified by the clients / users (Kelly and Mala, 2001. For instance, some buildings are required to solve space requirement problem. Buildings, generally once they have been completed are expected to perform certain function for a certain period. However, a building must be maintained to keep it in optimal operation. Building maintenance is inevitable as the need for maintenance will only intensify as the value of the building must be preserved for it to be meaningful to its users (and owners) since:

\section{"Even before a building is completed, Nature begins to destroy it systematically, and gravity, wind and seismic movement constantly test the stability of the structure. The ultraviolet wavelengths of sunlight fade and decompose organic building materials through molecular breakdown'” (Allen, 1995 and 2005).}

Accordingly, birth, growth, maturity, decline, decay, death, and rebirth are fundamental stages in all natural cycles and so too with buildings, although humans like to keep the cycle under control through maintenance until its death suits human purposes (Allen, 1995 and 2005). It is not only nature that destroys buildings; buildings are also destroyed by human activities. Buildings may not perform satisfactorily as a result of inadequate design, poor workmanship, defective materials and components, wrong installations and applications and the failure to provide the required maintenance. However, assuming the initial design was adequate for the intended use, the quality of workmanship was high, the materials and components selected were of high quality and installed properly, any inconsistencies from the predicted service life can be attributed to maintenance (Kalinger, 1997). According to Scrhrag, Smith and Stollenwerk (2007), new buildings are often beautiful, meet the required energy standards and are functional for the occupants are state-of-the--art and stakeholders are happy, but behind the scenes are the maintenance requirements of the buildings. Maintenance, therefore, is essentially required to delay decay, defects, deterioration and failure to ensure that buildings perform optimally throughout their life cycle so that they represent value to the various stakeholders' and, notably, the users.

Maintenance means different thing to different people. However, in this research, maintenance is defined as the required processes and services undertaken in order to preserve, repair and care for building's structure and components after completion or after any renovation, repair, refurbishment, conversion or replacement to current standard to enable it to serve its intended function throughout its entire life-span without drastically upsetting its basic features and use (Rakhra, 1983 and Olanrewaju, 2009). From this definition it is clear that maintenance is a value-added initiative and that the users are the main reason for initiating maintenance. Management on the other hand is concerns with the effective and efficient utilization of resource in order to attain the set objectives. Maintenance management is not exceptional to this. Thus building maintenance management can be defined as the process of planning, directing, leading and coordinating organizational resources towards building maintenance so that the building will continue to serve its intended purposes effectively and efficiently. Building maintenance management is goal-driven and, like the general planning process, it includes components for data collection, strategy evaluation, programme selection, implementation and feedback. Maintenance management can, however be classified into maintenance technology, which is the tactical aspect of the process and the main-stream management aspect of the process. The management is a problem-seeking and problem-solving process.

The major emphasis of building maintenance management is on the building being perceived a as a means to an end, not an end in itself and to view the building as an asset or facility rather as a burden. The definition of maintenance management can thus be depicted diagrammatically as shown in Figure 2. This definition suggests that maintenance management is a process that makes use of resources / in put (i.e. time, material, labour and money) and converts (process) them into outcomes (reliability, safety, function, comfort and convenience). At each stage, information it required either as feedback or feed forward. The Figure also suggests that the maintenance management process has no beginning or end. However, in practice when to begin maintenance requires a complex thought process as the decision involves viewing the building, the maintenance and university's corporate objectives concurrently.

The growth of recognition for building maintenance management has evolved to a great extent from government investment in maintenance of public buildings including the university buildings. However, the size and complexities of buildings that require maintenance in Malaysia are huge and are the increase irrespective of the sector. For instance, Ahmad, Nur Azfahani and Nur Haniza (2006) opined that in Malaysia, maintenance problems in buildings are common regardless of their size, location and ownership. Hamilton and Wan Salleh (2001) noted that the list of buildings that 
lack proper maintenance in Malaysia is countless. Cursory perusal of Malaysian newspapers will suggest the extent of the unfitness of buildings in Malaysia ( The Star, 2007, April 12; New Strait Times, 2007, May 4; The Star, 2008, June 16; The Star, 2007, April 20; New Straits Time , 2008, August 22; New Straits Time, 2008, June 19; New Straits Times, 2008, September 9; The Star, 2008, August, 28; The Star, 2008, June, 4; New Strait Times, 2008, September, 15; New Straits Times, 2008, September, 19). The Ministry of Housing and Local Government received between 2400 and 4500 maintenance complaints each year over the last five years (Chuan, 2008). That means for the last five years it has received more than 20,000 maintenance complaints. Perhaps many were also not reported. Although there is no comparable evidence for other ministries and government agencies, it could be concluded that they are facing a similar degree of maintenance woes. In fact, as a result of the malaise of the incessant maintenance problems facing public buildings, the (immediate) Prime Minister, Datuk Abdullah Badawi, ordered the inspections of all public buildings to ascertain their condition (New Strait Times 2007, May 4). While there is not comparable numerical data on the state of disrepair, decay, deterioration and unfitness of the university buildings in Malaysia, it is possible that they are suffering from a similar degree of care and neglect as other public buildings. This assertion could be further reinforced considering that public universities like public assets depend on government interventions in order to build, operate and maintain their buildings. Public universities depend on their annual budget for operating, development and maintenance costs.

Previous studies on maintenance management of public universities have suggested that the procedure used for university buildings were no different from other public buildings in Malaysia. That is that they are either corrective, time or condition based or their combination. Based on an empirical research, Ishak (2006), observed that the maintenance management procedures for university buildings are planned maintenance, contingency service, corrective, routine and preventive and corrective maintenance. Similarly, Zakaria, Mohamed, Ali (2006a and 2006b) concluded that the ways in which the maintenance of university buildings are managed as corrective, service, preventive and routine. Ruslan (2007) found that universities in Malaysia were still managing their facilities in the traditional ways. The traditional ways he referred to is interpreted to mean the corrective / reactive and condition based. However, while corrective maintenance is a failure based approach, predictive, time and proactive maintenance are condition based. Corrective maintenance is initiated after the building has failed and is intended to restore the building to it original condition. What this means is that maintenance is initiated when the building has failed to perform its intended function due to decay, deterioration or defect or any combination of these. This approach to maintenance is in many cases very expensive, and usually leaves the users less satisfied. Unfortunately, this is the most common approach to maintenance when a building has failed to perform to the expected standard. Condition-based maintenance on the other hands is a type of maintenance initiated as a result of some knowledge of the condition of the building on the basis of inspection prior to failure. As long as the physical parameters, of the building where found to be within specification, it will be considered to be "fine" and no maintenance action will be taken. Maintenance will only be initiated if the physical condition of the building is deteriorating, decaying or failing.

However, stock condition at best provides only a snap shot of the condition of a building during the inspection period. It is difficult to assess the amount of risk posed by an identified non-critical problem to future operations and productivity (Reffat, Gero and Peng, 2004). A non-critical problem during inspection might deteriorate further or become more serious during the actual implementation due to time lapse and error of measurement as a result of visual inspections. Under the condition based maintenance policy the required information is not usually sufficient and convincing to draw a realistic conclusion. The maintenance needs that usually revealed through a condition survey are often in excess of the available budget. The validity and reliability of the determination of the maintenance budget through stock inspection are questionable. Also, O'Dell (1996) opined that stock condition survey could underestimate the volume and costs of maintenance need by as high as $60 \%$ of the actual works / costs (Jones, 2002).

Therefore, the existing practices are not value-added approach to maintenance because maintenance depends on the existing of sickness of the building before treatment is recommended. This culminates in poor service delivery and poor user satisfaction and an increase in maintenance backlogs. However, what is critical to the users of client-occupiers of a building is the ability of the building to efficiently and effectively support the performance of the activities within and around the building and not necessarily the physical condition of the building per see (Chapman Beck, 1998; Jones, 2002 and Jones and Sharp, 2007). A building is an enabler and facilitator of human activities. It provides the enabling temperature, humidity, lighting and ventilation necessary for people to live and work productively and efficiently (See also Barrette, 1992 cited in Amaratunga and Baldry, 1998). Users tend not to be satififiesd when the building failed to meet their needs and wants. Criteria including temperature, air quality, lighting, noise and comfort in a building increase users' productivity (Leaman, 1995). A success building is therefore, a building that meet (and exceed) the complex requirements of the users. Thus, what is critical in maintenance management is to meet the complex requirements of the users and building itself effectively and efficiently. According to Flanagan and Jewell (2005), a building can still be used even though the fabric has deteriorated significantly. Then (2002) also opined that ultimate essence of building management is the fitness for purpose of the building for the user. The current approaches to building maintenance do 
not address maintenance as value added service and failed to consider the perceptions and expectations of the users in decision making. The input, perceptions and expectations of the users and owner-occupiers cannot be compromised if value is to be achieved.

Authors including Seeley (1987), Mills (1994) and Wordsworth (2001) have questioned the validity and of any maintenance policy that does not consider the users in the formulation of the maintenance management system. For instance many parties contributes in the decision making process which govern the design, construction and maintenance of building. But at the end of the line he users are that people that will be affected by such decisions (Mohmoud, 1998). The client is on the one hand, legally responsible for maintenance while, on the other hand, he or she might not be aware of the maintenance problems involved. Thus building ceases to be useful if it cannot provide those functions as required by users. Considering the condition of the building as the main reason for initiating maintenance service is accepting maintenance as a burden that has no value to add to the building. In fact, condition based maintenance system has various other shortcoming including inconsistency in data collection, unrealistic assumption regarding data accuracy, software not being able to interrogate or manipulate data and over emphasized detail that might not even be required (Marshall, Worthing and Thomas, 1996 and Chapman and Beck, 1998). Besides, the physical condition of the building is just a symptom and not the cause of the defects. For efficiency and effective, it is the root causes that require consideration, otherwise wrong solution will be administered to the wrong ailment.

Under the condition based maintenance management, the thrust on combating the physical deterioration and decay of the building not just enhancing its value. Maintenance must be initiated on the basis of the value of the building to the users. In this way the building and associated maintenance will be regarded as investment. Maintenance is a value added initiate to the building and the users. By ensuring that users' activities are well performed. A value based maintenance management system goes beyond the current condition based system and the availability of funds, it involves recognizing maintenance needs as factor of production without the value of a building cannot be sustained. A factor of production enhances productivities and contributes to profit making and saving (Sherwin, 2000). In other words it is a comprehensive and structured system to long - term management of building s as tools for efficient and effective delivery of value to the clients, users and general public. In practice and principle, a maintenance progamme can be initiated at all levels or at any time in the building's life cycle with diminishing level of return. The cost of implementation of the maintenance programme is very low if the maintenance programme proceeds from the value approach to corrective approach, the possibility of positive savings declines substantially and the cost of implementing the maintenance programme increases (Figure 3) (Olanrewaju,2009). The next section draws together the major themes of the paper to highlight the issue that need to be addressed with the respect to value-based maintenance management. The focus of modern forward thinking user and clients extends beyond building technology, corrective and condition based maintenance

\section{Synopsis and Further Research}

In anticipation of the main research, this paper has outlines a plan to proceed with the research. The shortcomings of the existing practices have been outlined. Lack of sufficient resources has forced government today, to compel their agencies, departments and ministries to maintain their building in the most cost-effective way. As the cost of constructing new facilities increases, maintaining the existing ones has become more prominent as an alternative to the service lives of the buildings. It is not always cost-effective to demolish and reconstruct the existing ones. Maintenance seeks to delay the replacement of building as well as deferring expenditure on new build. A building is the representation of a organization's value systems and the performance of the university building no doubt depict how valuable the university considers the contribution of its buildings towards achieving the core objectives of its business.

Thus there is a need for systematic and holistic maintenance management for building that based on the principle of value. Value involves the amount of money associated with how effectively and efficiently a function or / and service meets the users' or customers expectation (Bateman and Snell, 2009) and perceptions. Buildings are procured or occupy to solve some technical problems as identified by the users / clients. To most not-occupiers clients, buildings are procured to make profit. Building users are the entity or group of individuals or organization who are interested in the adequate functioning of the building. They are affected by the performance of the building and the building is also affected by the activities of users. They have the potential and capability to take a action or decision if their value system is not adequately met. It is the correct functioning of the building that the users desire not the physical condition of the building. To the extent that the building is capable of allowing the user to perform their function, then the building can be said to be valuable. In other words, the building can be said to be adding value to the activities taking place inside or around it. Of what value is a classroom that is not conducive to student learning? The more you meet the user's expectations (measure in terms of quality, speed, reliability, safety and function, comfort, cost, etc) and perception at less cost, the more value is delivered to the users. In other words, the more the users' maintenance performance and expectations are achieved (effectively) with fewer resources (efficiently), the higher the value you add to the maintenance service. The need for value based maintenance management will only intensify as the need for 
maintenance increases as maintenance is inevitable, and thus a proactive, efficient and effective approach is highly necessary since the demand of the modern users is for high quality service (and goods) that are delivered on time and which cost less.

In conclusion, this paper has been able to establish that the current maintenance management systems for university buildings in Malaysia are corrective and condition based. It is also established that the condition based maintenance management is reactive rather than proactive and systematic. Considering the condition of the building as the major focus of maintenance is to regard maintenance as burden and to limit maintenance to the technological aspect of the process. Maintenance management is not usually regarded as part of the top management functions or duties in most public organizations rather it often regarded as operational function. It only receives management attention when everything has gone wrong. Users will not be satisfied with the quality of the service they are receiving and the maintenance backlog will be on the increase unless and until the maintenance management reflects the new thinking of the performance of the building which is the desirability of the buildings for the users. The value based maintenance management model takes into account the condition of the buildings, its performance, the users' value systems and the resource used to meet the needs. It involves the efficient and effective utilization of a organization's resources by planning, directing, controlling and organizing in order to meet the maintenance needs of the building users since the ultimate essence of the building is to enable the its users to perform their task effectively and efficiently. Public universities organizations must consider and accept maintenance as factor of production that require strategic attention like other organization's resources.

The prime aim of maintenance management is the effective and efficient allocation of resources to meet maintenance needs. However, the management of the resource has often been based on outcome of the condition survey. On the other hand, maintenance needs established through the condition survey are in fact, often in excess of the available resource among shortcomings. Thus the only feasible alternative method of allocating and determining maintenance resources is to base maintenance needs on the user value systems in terms of whether the building can still continue to support the user functional value system. Buildings are only valuable as a result of the service they provide, and failure will render the existence of the building insignificant if not even useless (Wordsworth, 2001). Therefore, maintenance should be initiated only if the building will no longer facilitate the users in performing their primary tasks. The corporate objectives of a university have to place building performance in a strategic position. Therefore, maintenance is inevitable, and in order to improve and sustain productivities, service delivery and satisfaction of the users, maintenance must be positively managed. The error and inadequacies inherent with the stock condition survey is too much to be ignored. To continue to based on the basis of physical inspection cannot in any way delivered value for the stakeholders and will continue to encourage poor service deliveries.

Maintenance cannot be blamed if things go wrong; rather it is the management of the maintenance process that should be blamed! However, there are limitations to this paper. First, the paper is based on literature. Though the literature are mainly empirical regarding the state of maintenance management of the university buildings in Malaysia, but there is the need for empirical studies to determine if the principle of user value system can form major thrust of initiating maintenance. In, addition, the empirical studies by the previous researchers do not includes most of the public universities, also there could be the tendency that somewhere a or some universities has/have better approach to building maintenance. These issues and more will be addressed in the main research.

\section{References}

Ahmad Abdullah Badawi. (2006, February 20). Billions Wasted to Repair Buildings and Amenities. The Star, 2006.

Ahmad, R, Nur Azhahani, A and Nur Haniza, I. (2006). The Effects Design on The Maintenance Of Public Housing Buildings In Malaysia-Part One. Journal of Buildings Engineer, April, 2006.

Allen, E. (1995 and 2005). How Buildings Work: the Nature Order of Architecture, $1^{\text {st }}$ and $2^{\text {nd }}$ edn. Oxford: Oxford University Press.

Bateman, T. S. and Snell, S. A. (2009). Management: leading and collaborating in the competitive world, $8^{\text {th }}$ Edition. New York: McGraw Hill / Irwin.

Barrett, P. (1 992). Development of a Post Occupancy Building appraisal Model. In Dilanthi Amaratunga, D and Baldry, D (1998). Appraising The Total Performance of Higher Educational Buildings: A Participatory Approach Towards A Knowledge-base System. COBRA .98 ISBN 1-873 640-23-4.

Chuan, O. K. (The Minister of Housing and Local Government) (2008, May 9 pN13). Call for Check on Buildings: architects push for inspection every five years. The Star pN33.

Hamilton, B and Wan Salleh, W. I. (2001). Maintenance of building important. National House Buyers Association. accessed on 09 / 06 / 08. Available at http://www.hba.org.my/archive/focus/COB/pg1.htm 
Jones, K. (2002). Sustainable Buildings Maintenance. In: Kelly, J., Morledge, R. and Wilkinson, S. (2002). (ed) Best Value in Construction. London; Blackwell Publishing.

Jones, K. and Sharp, M. (2007). A New Performance Based Process Model for Built Asset Maintenance. Facilities, Vol. 25 No. 13/14, pp525-535.

Wordsworth, P. (2001). Lee's Building Maintenance Management, $4^{\text {th }}$ Edn. Oxford: Blackwell Science Limited.

Kalinger, P (1997). The Benefit of Preventive Roof Maintenance, NRCC-40627-5 Building Better Roofs: IRC Technical Seminar, 11 Cities Across Canada September 1996-February 1997, pp1-9. http://nrc-cnrc.gc.ca/ircpubs

Kelly, S. R \& Male, S. P. (2001). Value Management in Design and Construction: The Economic Management of Project 1st Edn. London: E and FN Spon.

Leaman, A (1995). Dissatisfaction and office productivity. Facilities. Volume 13 No. 2. pp $13-19$.

Mills, E. D. (ed. 1994). Building Maintenance and Preservation; a guide to design and management, $2^{\text {nd }}$ Oxford: Butterworth-Heinemann 1994.

Mohmoud, M. I. (1998). Assessment of the Factors Influencing the Maintenance Programme of a Large University Building in Riyadh", Construction Management and Economic, Vol. 15, issue 6, pp 673-679.

New Straits Times. (9 September, 2008). No you don't: developer get court injunction to stop residents from "taking over condo" p.

New Straits Times. (2007, May 4). Cracks Show Up on Jalan Duta Court Complex Wall p14.

New Straits Times. (2008, August 5). 510 Heritages Building Need Help.

New Straits Times. (15 September 2008). Dirties among seven nations. p16.

New Straits Times. (19 September, 2008) 92 Historical Buildings to Be Restored.

O'Dell, A. (1996). Taking Stock: a Review of stock condition survey methods in the UK. User-oriented and Cost Effective Management, Maintenance and Modernization of Building Facilities, CIB W70, Kesinki 1996 Symposium, 2-3 September 1996.

Olanrewaju, A. A. (2009). Maintenance Management of University Buildings, Article accepted for publication in Journal of Building Appraisal.

Rakhra, A S (1983) Some economic aspects of the rehabilitation of buildings. CIB83. In Proceedings: To Build and Take Care Of What We Have Built With Limited Resources. V. 1A: Renewal, Rehabilitation and Maintenance, 9th CIB Congress. pp77-88. Available at: http://www.nrc-cnrc.gc.ca/obj/irc/doc/pubs/nrcc23437/nrcc23437.pdf Accessed on $11 / 05 / 2008$.

Reffat, R. M., Gero, J. S. and Peng, W. (2004). Using Data Mining On Building Maintenance During The Building Life Cycle, In Proceedings of the $38^{\text {th }}$ Australian and New Zealand Architectural Science Association (ANZASCA) Conference, School of Architecture, University of Tasmania, Tasmania, Australia, pp.91-97.

Ruslan, B. N. (2007). Campus Facilities Management Experience. In Proceedings of National Assets and Facility Management (NAFAM, 2007). Held on the $13^{\text {th }}-14^{\text {th }}$ of August, 2007. Kuala Lumpur.

Schrag, S., Smith , K and Stollenwerk, B. (2007). Designing for the care and maintenance of building. Accessed on $13 /$ 05 / 2008. Available at: www.allbusiness.com/energy-utilities/energy-utility-regulation-policy/5496916-1.html - 73k

Seeley, I. H. (1987). Building Maintenance, $2^{\text {nd }}$ Edition, Houndmills: Macmillan Press Limited.

The Star (2007, April 12). Immigration Headquarters Havoc: leak on the seventh floor sends water down five levels pN4.

The Star. (16 June 2008). Abandoned Quarters Now An Eyesore. pM12

The Star. (20 April 2007). JB Hospital "sick" again. pN35.

The New Straits Times. (2008, June 19). Downright Filthy Business p5.

The Star. (28 August 2008). Residents See Red Over Piping Works. pM6.

The Star. (22 August 2008). Solution To Stinking Woes In Sight. pM8.

The Star (2008, June 4). Ambrin Promises Thorough Check: Inspection team to check 94 public buildings pN14.

Then, S.S. (2002). Post-Occupancy Evaluation (POE) In: Kelly, J., Morledge, R. and Wilkinson, S (2002). (Ed) Best Value in Construction. London; Blackwell Publishing. 


\begin{tabular}{|c|c|c|c|c|}
\hline \multirow{2}{*}{ Value } & $=$ & Benefits & \multirow{2}{*}{ or } & Quality + Functions \\
& & Investment & & Total cost \\
\hline
\end{tabular}

Figure 1. Value Concept

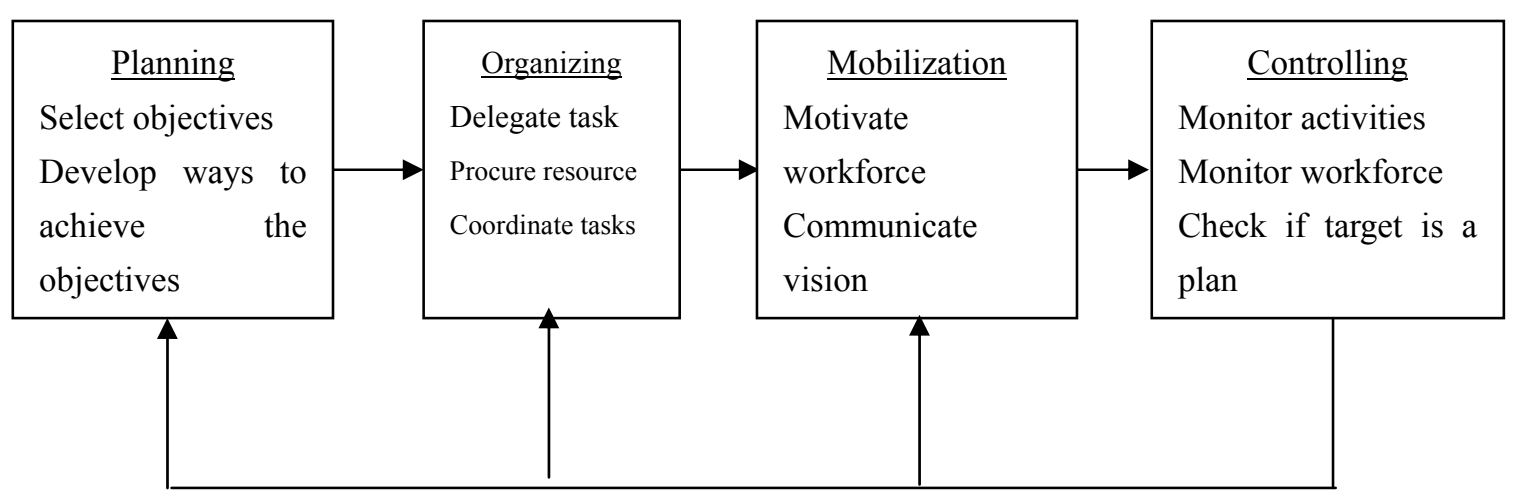

Figure 2. maintenance management definition model

Time (period of intervention incur)

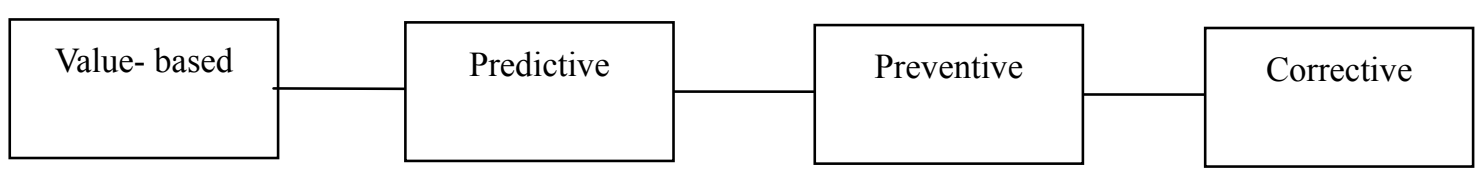

Cost (incur in long time)

Figure 3. time-cost maintenance intervention framework 